\title{
Aspectos éticos e econômicos da tributação sob uma perspectiva hoppeana
}

\author{
Ethical and economic aspects of taxation from a hoppean perspective
}

Aspectos éticos y económicos de la fiscalidad desde una perspectiva hoppeya

Felipe Freitas de Araújo Alves ${ }^{1}$; Luis Felipe Ramos Cirino²; Caio da Silva Zuanetti ${ }^{3}$; Germano Leão Hitzchky Madeira ${ }^{4}$

\section{RESUMO}

O presente trabalho tem como objetivo analisar a ética e a economia da tributação sob a luz dos ensinamentos desenvolvidos por Hans-Hermann Hoppe. Com supedâneo na Ética Argumentativa Hoppeana, o artigo aborda as consequências econômicas da espoliação legal, valendo-se, para tanto, da metodologia desenvolvida pela Escola Austríaca de Economia, corrente de pensamento econômico da qual Hoppe faz parte. Ademais, Hans Hoppe deixa claro que a tributação deve ser vista - acima de tudo - como um meio de destruição da propriedade e formação de riqueza. Em suma, as obras de Hans-Hermann Hoppe caracterizam-se por uma intransigente defesa moral e intelectual do direito de propriedade privada, cujas lições pouco ortodoxas sintetizam, por um lado, uma profunda crítica ética ao ato de tributar e, por outro, a destruição de riqueza que esse instituto causa.

Palavras-chave: Economia; Ética; Hans-Herman Hoppe; Tributação.

\begin{abstract}
The present paper aims to analyze the ethics and economics of taxation in the light of the teachings developed by Hans-Hermann Hoppe. With a background in Hoppean Argumentative Ethics, the paper approaches the economic consequences of legal plunder were presented, making use of the methodology developed by the Austrian School of Economics, a current of economic thought that Hoppe is part. Furthermore, Hans Hoppe makes it clear that taxation should be seen - above all - as a means of destroying property and building wealth. In short, Hans-Hermann Hoppe's works are characterized by an uncompromising moral and intellectual defense of the right to private property, whose unorthodox lessons synthesize, on the one size, a profound ethical criticism of the act of taxing and, on the other, destruction of wealth that this institute causes.
\end{abstract}

Keywords:

Keywords: Economy; Ethic; Hans-Hermann Hoppe; Taxation.

\section{RESUMEN}

El presente trabajo tiene como objetivo analizar la ética y la economía de la tributación a la luz de las enseñanzas desarrolladas por Hans-Hermann Hoppe. Con un sustituto en la Ética argumentativa de Hoppe, el artículo aborda

\footnotetext{
${ }^{1}$ Mestre em Direito e Doutorando em Educação pela Universidade Federal do Amazonas (UFAM), Manaus/AM - Brasil. E-mail: Felipe.jhs@hotmail.com

${ }^{2}$ Doutor e Mestre em Direito e professor do curso de pós-graduação em Direito Civil da Universidade de São Paulo, São Paulo/SP - Brasil. E-mail: luisfelipecirino@gmail.com

${ }^{3}$ Especialista em Direito pela Escola Brasileira de Estudos Jurídicos. E-mail: caio_z@hotmail.com

${ }^{4}$ Mestrando em Políticas Públicas na Universidade Estadual do Ceará (UECE), Fortaleza/CE - Brasil. E-mail: germanomadeira@hotmail.com
} 
las consecuencias económicas del despojo legal, haciendo uso de la metodología desarrollada por la Escuela Austriaca de Economía, una corriente de pensamiento económico de la que Hoppe forma parte. Además, Hans Hoppe deja claro que los impuestos deben verse, sobre todo, como un medio de destrucción de la propiedad y formación de riqueza. En definitiva, las obras de Hans-Hermann Hoppe se caracterizan por una defensa moral e intelectual intransigente del derecho a la propiedad privada, cuyas lecciones poco ortodoxas sintetizan, por un lado, una profunda crítica ética del acto tributario y, por otro, la destrucción de la riqueza que provoca este instituto.

Palabras clave: Economía; Principio moral; Hans-Herman Hoppe; Impuestos.

\section{INTRODUÇÃO}

A tributação é o ato pelo qual o Estado retira (compulsoriamente) dos indivíduos parte de seu patrimônio com o intuito de destiná-la aos cofres públicos. A finalidade última da tributação é sustentar o aparato estatal e promover os direitos previstos na Constituição da República de 1988, os quais variam desde programas de redistribuição de renda, até o fornecimento de saúde, educação, previdência social etc.

No entanto, Hans-Hermann Hoppe, autor cujos ensinamentos serão objetos deste trabalho, apresentou - e ainda apresenta - ao longo da sua trajetória intelectual um robusto estudo que aponta vários problemas para a tributação.

No mundo todo várias nações vêm adotando um Estado de Bem-Estar Social cada vez mais inchado, e que está se mostrando insustentável no longo prazo. Com os governos avocando para si cada vez mais responsabilidades, o aparato estatal tem crescido assustadoramente, de modo que o resultado tem sido governos com déficits bilionários e à beira da ruína econômica. A conta dessa imprudência fiscal é cara e será paga, obviamente, pelos cidadãos e suas futuras gerações.

Diante desse cenário, algumas perguntas surgem. A tributação seria economicamente eficiente? 0 Estado conseguiria alocar os recursos arrecadados de maneira racional e mais eficiente que os próprios indivíduos o fariam privadamente? Mais do que isso, seria ético o ato de tributar? Poderiam algumas pessoas, representando o poder estatal, exigir parte do patrimônio de seus iguais?

Essas e outras perguntas serão objetos de reflexão neste trabalho, todas elas analisadas sob a ótica do pensamento hoppeano.

Não obstante, além das obras de Hans Hoppe, inúmeras outras de autores diferentes, que também tratam do tema, foram mencionadas no presente trabalho, ainda que tangencialmente. Merece destaque, ademais, os autores e obras da Escola Austríaca de Economia, cujos ensinamentos influenciaram o pensamento de Hoppe e dão suporte para a análise econômica do presente artigo.

A síntese inescapável a que esse trabalho conduz é claramente contra majoritária, na medida em que se afasta do pensamento ortodoxo (mainstream) ensinado no ambiente acadêmico brasileiro. Entretanto, os argumentos apresentados dão importante contribuição para o debate e enriquecem o estudo do direito.

Por fim, a metodologia utilizada consiste numa revisão eminentemente bibliográfica de cunho exploratório. Para isso, analisar-se-á o pensamento de Hoppe, bem como sua teoria sobre a Ética, concluindo com a metodologia austríaca para análise dos impactos econômicos causados pela tributação. 
Espera-se, portanto, que este trabalho seja uma colaboração acerca dos estudos sobre a tributação e que ainda possa ajudar quem pretenda se aprofundar nos aspectos éticos e econômicos da espoliação legal, sobretudo para conhecer (e reconhecer) o pensamento desse grande intelectual que é Hans-Hermann Hoppe.

\section{HANS-HERMANN HOPPE E A ÉTICA ARGUMENTATIVA}

Hans-Hermann Hoppe, filósofo e economista alemão, nasceu no dia dois de setembro de 1949 em Peine, na antiga Alemanha Ocidental. Estudou filosofia, sociologia, história e economia na Universitätet des Saarlandes, em Saarbrucken, na Goethe-Universität, em Frankfurt, e na Universidade de Michigan, em Ann Arbor, nos Estados Unidos. Graduou-se em sociologia e economia em 1981 e obteve seu Ph. D. em filosofia em 1974, ambas pela Goethe Universität.

Hoppe foi aluno (e orientando) do filósofo e sociólogo alemão Jürgen Habermas, de modo que este último teve certa influência sobre o trabalho de Hoppe. Um dos mais importantes estudos desenvolvidos por Hans Hoppe - para não dizer o maior - foi a teoria sobre a ética, conhecida como "Ética Argumentativa Hoppeana".

Como o próprio nome sugere, esse trabalho foi influenciado pela teoria do "Agir Comunicativo" de Habbermas. No entanto, em que pese essa influência, ambas as teorias são praticamente opostas em suas conclusões. Ao passo que Habbermas, integrante da Escola de Frankfurt, deriva sua ética para legitimar a democracia e outros regimes intervencionistas, como o socialismo, Hoppe toma caminho oposto e oferta ferrenhas críticas às constantes violações do direito de propriedade privada existentes nesses regimes. Por esse e outros motivos, Hans-Hermann Hoppe passa a ser o principal defensor vivo do Libertarianismo, além de um dos principais expoentes da Escola Austríaca de Economia.

Ao perceber a falência moral e intelectual do juspositivismo e do intervencionismo, Hoppe se torna libertário e vê as portas das universidades alemãs se fecharem, mesmo com o currículo que o qualificava para o posto.

Com isso, em 1986 Hoppe se muda para os Estados Unidos e se torna aluno do economista Murray Newton Rothbard (1926-1995), com quem colaborou de forma assídua até a morte deste. Influenciado também pela praxeologia de Ludwing von Mises (1881-1973), Hoppe lecionou em várias universidades, como a Università di Bologna, Johns Hopkins University e University of Nevada, sendo professor emérito de economia desta última.

Como autor de livros e artigos, Hans-Hermann Hoppe possui vasta publicação, dentre elas The Economics and Ethics of Private Property: Studies in Political Economy and Philosophy (1993), A Ciência Econômica e o Método Austríaco (2010), Uma Teoria do Capitalismo e do Socialismo (2013), O que Deve ser Feito (2013) e Uma Breve História do Homem: Progresso e Declínio (2018).

Talvez a sua mais famosa - e polêmica - obra seja Democracia, o Deus que Falhou: A Economia e a Política da Monarquia, da Democracia e da Ordem Natural (2014). Nesta obra, Hoppe tece pesadas críticas à democracia, descrevendo-a como "uma máquina de destruição de riqueza, de desperdício econômico e de empobrecimento" e conclui identificando-a "como uma causa sistemática de corrupção moral e degeneração" (HOPPE, 2014, p. 13). 
Nesta obra Hoppe analisa a natureza, os incentivos e os problemas econômicos e éticos da democracia, da monarquia e do que ele chama de ordem natural (podendo também ser referida como "anarquia ordenada", "anarquismo de propriedade privada", "anarcocapitalismo", "autogoverno", "sociedade de leis privadas" e "capitalismo puro") HOPPE, 2014, p. 27). Ele explica o porquê de o sistema democrático ser pior do que o monárquico, além de enfatizar que ambos são piores do que a ordem natural.

Economicamente falando, a democracia gera péssimos incentivos. Como o governante ocupa sua função transitoriamente e não tem a propriedade privada do aparato estatal (os bens são públicos) não há incentivos para a responsabilidade financeira. Ademais, como a ocupação de cargos públicos (estes que trazem consigo enormes privilégios se comparados com a atividade particular) é aberta a qualquer pessoa, há um incentivo para que os indivíduos despendam esforços para almejar tais cargos, o que tende a aumentar o tamanho do estado. Por conta desses e outros motivos, há uma tendência no aumento da tributação e de uma maior tolerância das pessoas quanto ao pagamento de impostos cada vez maiores.

Superado esse arrazoado introdutório acerca da vida e obras do filósofo, e a fim de permitir compreender se a tributação é eticamente defensável segundo os ensinamentos de Hans-Hermann Hoppe, analisemos a sua teoria da Ética Argumentativa.

Primeiramente, cumpre esclarecer o conceito de contradição performativa, uma vez que Hoppe se vale desse método para provar a sua teoria.

Uma contradição performativa é uma contradição entre o que é dito e o que é pressuposto pela pessoa no ato de dizer isto. Ou seja, a pessoa ao mesmo tempo assume a invalidade de uma proposição explicitamente (com o argumento proferido) e a validade desta proposição implicitamente (com a pressuposição que ela necessariamente faz ao entrar em uma argumentação, ao propor um argumento). Para exemplificar, é como se eu dissesse a alguém "eu não ajo"; nesse exemplo, o que foi dito através de argumento ("eu não ajo"), se contradiz com a pressuposição necessária para realizar aquela conduta (eu preciso agir para poder falar).

Sendo assim, o que Hans Hoppe demonstrará é que a sua Ética Argumentativa é a única que não cai em contradição performativa, ou melhor dizendo, que não será ilógica.

Com dito acima, Hoppe foi muito influenciado pela praxeologia de Ludwing von Mises, de modo que o argumento ético trazido por Hoppe parte do estudo de como as pessoas agem e da forma como escolhem entre seus possíveis objetivos.

A praxeologia, segundo Mises:

É a ciência de todo tipo de ação humana. Toda decisão humana representa uma escolha. Ao fazer sua escolha, o homem escolhe não apenas entre diversos bens materiais e serviços. Todos os valores humanos são oferecidos para opção. Todos os fins e todos os meios, tanto os resultados materiais como os ideais, o sublime e o básico, o nobre e o ignóbil são ordenados numa sequência e submetidos a uma decisão que escolhe um e rejeita outro. Nada daquilo que os homens desejam obter ou querem evitar fica fora dessa ordenação numa escala única de gradação e de preferência. A moderna teoria de valor estende o horizonte científico e amplia o campo dos estudos econômicos. Da economia política da escola clássica emerge a teoria geral da ação humana, a praxeologia. (MISES, 2010, p. 23). 
Hoppe, em complemento aos ensinamentos de Mises, explica o status de axioma que é dado à ação humana, na medida em que não é possível negar que os homens agem, porque o próprio ato de assim fazer seria uma ação. Portanto, é impossível revogar a validade desta proposição (HOPPE, 2010, p. 20). Além do mais, estão implícitas no axioma da ação humana várias categorias que podem ser constatadas através da dedução do argumento, tais como valores, fins, meios, escolha, preferência, custo, lucro e prejuízo. (HOPPE, 2010, p. 22)

Em suma, tais conceitos são verdades já implícitas neste axioma, que não podem ser negadas sem que se negue ele, ou seja, sem que se caia numa contradição performativa. Esses argumentos, ademais, que hoje são de razoável compreensão, demandaram enorme esforço intelectual para serem explicitados. (HOPPE, 2010, p. 21)

Para ilustrar a questão, imaginemos que alguém tenha uma hierarquia de todos os possíveis fins que ela pode buscar em uma determinada situação (jogar tênis, comer um risoto, assistir um filme etc.), quanto mais ela prefere um fim em relação aos outros, mais valor ela dá a ele, e mais alto ele fica em sua hierarquia; a pessoa, então escolherá entre os fins, escolhendo aquele que está mais alto, e utilizando os meios necessários para atingi-lo (sendo que, pelo menos o seu tempo, deve ser utilizado para ir em busca deste fim). Esta é, portanto, a base da teoria praxeológica. Seres humanos utilizam recursos escassos para atingirem fins desejados e esse objetivo (fim desejado) a ser atingido é mais valioso para o agente do que o seu custo despendido para agir. Todas estas proposições estão implícitas no axioma fundamental da ação humana.

De outro giro, outra importante implicação do axioma da ação humana é a de que meios são escassos, ou seja, um meio não pode ser utilizado para atingir todos os fins ao mesmo tempo. Isso ocorre, pois, se um meio pudesse ser utilizado para se atingir todos os fins, já teríamos os atingidos, ou seja, não estaríamos agora argumentando e agindo. O princípio da escassez está, portanto, implícito no axioma da ação humana, pois negá-lo seria afirmar que humanos não agem, o que, já sabemos, é falso.

Nesse sentido, conflitos surgem devido à escassez de bens, notadamente no sentido de que a utilização de um bem escasso impede que outra pessoa o utilize. Se os meios não fossem escassos, todas as pessoas atingiriam todos os fins possíveis e desejados, sem que a ação de qualquer indivíduo interferisse ou limitasse a ação do outro. Em outras palavras, não haveria conflitos.

Analisemos, a título de ilustração, o caso de Robinson Crusoé. Enquanto sozinho na ilha o marinheiro não possui qualquer limitação sobre as suas condutas, podendo fazer o que bem entender a qualquer hora. Obviamente, a questão muda de figura a partir do momento em que Sexta-Feira aparece, muito embora o surgimento dele ainda seja pouco relevante enquanto não houver escassez dos demais bens. Caso a ilha fosse o Jardim do Éden, por exemplo, no qual há superabundância de bens externos - estando ainda disponíveis gratuitamente à ambos - a utilização dos bens por Crusoé ou Sexta-Feira não alterará significativamente a disponibilidade de bens presentes ou futuros para o outro sujeito da ilha. Logo, em relação ao uso de tais bens, a existência de um conflito entre ambos nessa situação hipotética se torna praticamente impossível. Portanto, considerando que um conflito só se torna possível se os bens forem escassos, é somente a partir dessa premissa que surgirá a necessidade de formular regras que possibilitem a cooperação social ordenada e livre de conflitos (HOPPE, 1993, p. 381).

Entretanto, Hoppe ainda faz importante colocação, no sentido de que mesmo no Jardim do Éden, devido à escassez do próprio corpo e do tempo, haveria a possibilidade de conflitos. Crusoé não 
poderia, simultaneamente, pescar, comer uma fruta, construir sua casa, admirar o oceano, coletar madeira etc.. Considerando que Crusoé só possui um corpo para realizar as ações - assim como todos nós -, ele deverá fazer escolhas, de modo que somente poderia realizar essas ações de maneira sequenciada e não todas ao mesmo tempo. Por outro lado, além da limitação do meio utilizado para agir, há também a limitação pelo tempo, uma vez que o corpo não é indestrutível e nem possui saúde e energia eternas. Em outras palavras, o corpo tem tempo de vida limitado, motivo pelo qual o tempo se torna escasso. O tempo que utilizo para atingir determinado objetivo, reduz o tempo disponível para buscar outro objetivo, sendo que, quanto mais tempo se gasta para atingir o fim desejado, maiores serão os custos envolvidos na espera e maior deverá ser a satisfação esperada. (HOPPE, 2013, p. 23)

Portanto, partindo dessas premissas de que os bens são escassos e de que a escassez gera conflitos, emerge a necessidade por leis que resolvam tais conflitos e, consequentemente, surge o conceito de propriedade. Se, em verdade, o uso de bens por qualquer pessoa não excluísse (ou interferisse; ou restringisse) de alguma maneira seu uso por qualquer outra pessoa, a propriedade, então, não seria necessária. (HOPPE, 2010, p. 21-22)

Nesse sentido, Hoppe explica:

Para desenvolver o conceito de propriedade é necessário que os bens sejam escassos, de modo que seja possível surgir conflitos sobre o uso desses bens. É função dos direitos de propriedade evitar esses possíveis conflitos sobre o uso dos recursos escassos através da atribuição de direitos de propriedade exclusiva. A propriedade é, dessa forma, um conceito normativo, concebido para tornar possível uma interação livre de conflitos pela estipulação de regras de conduta (normas) mútuas e vinculativas em relação aos recursos escassos. Não é preciso observar muito para verificar que há, na verdade, uma escassez de bens, de todos os tipos de bens, em qualquer lugar, e assim se torna evidente a necessidade dos direitos de propriedade. Na realidade, até mesmo se assumirmos que vivemos no Jardim do Éden, onde haveria uma imensa abundância de tudo o que era preciso não apenas para sustentar a vida de alguém, mas para saciar cada conforto simplesmente estendendo as mãos para pegar 0 que fosse necessário, o conceito de propriedade teria que, necessariamente, ser desenvolvido. Pois até mesmo sob essas circunstâncias "ideais", cada corpo físico de um indivíduo ainda seria um recurso escasso e por isso existiria a necessidade de estabelecer regras de propriedade, ou seja, regras relativas ao corpo das pessoas. (HOPPE, 2010, p. 22).

Chegamos, pois, no cenário de que há a necessidade de se estabelecer normas a fim de evitar e resolver os conflitos em sociedade. Uma norma que evite conflitos é uma que, caso seja seguida por todos, não levará a conflito algum, ou seja, basicamente, a norma é livre de contradições internas. Ela estabelece, portanto, a alocação de recursos escassos.

Então, para a norma ser logicamente defensável ela deve evitar e resolver os conflitos, alocando os recursos escassos ao uso exclusivo e definitivo dos indivíduos, a fim de excluir dos outros o uso. Isto se chama direito de propriedade privada.

Uma lei que leve a conflitos é logicamente contraditória com o conceito de ação, e com o conceito de lei em si, logo, ao entrar em uma argumentação a respeito da legitimidade de leis, qualquer pessoa pressupõe a legitimidade de se evitar conflitos, não podendo argumentar a favor de uma lei que leve a conflitos, sem que caia em uma contradição performativa. 
Nesse momento, sabendo o que uma lei deve ser, Hoppe ensina que uma norma só pode ser justificada através da argumentação, ou seja, quando se busca resolver conflitos, envolve-se sempre mais de uma pessoa, de modo que a justificação das preposições são sempre intersubjetivas. Aqui existe outra pressuposição do ato de argumentar: todo o sujeito capaz de agir e falar pode participar da argumentação, e ninguém pode impedir um falante de exercer esta participação ou de introduzir ou questionar qualquer asserção por meio de coerção. Logo, numa argumentação entre indivíduos está implícito o princípio da não agressão, posto que rejeita-se a imposição da força e consagra-se o convencimento pela argumentação.

Ademais, quando se busca argumentar sobre uma ética, uma norma que prescreva as condutas que são permitidas e proibidas, pressupõe-se também que está deve ser universal, ou seja, aplicada a todos capazes de falar e agir, uma vez que todos têm o direito de participar da argumentação e argumentarem sem serem impedidos por meio de coerção.

Retornando ao exemplo de Crusoé na ilha, Hoppe explica que a tentativa de formular uma ética entre Crusoé e Sexta-Feira muda de figura, caso este último fosse um gorila. Caso o gorila queira ocupar o mesmo lugar que Crusoé na ilha, não haverá solução racional para o conflito. O uso da força é que ditará a o rumo da controvérsia. Ou Sexta-Feira vencerá esmagando e devorando Crusoé, ou Crusoé vencerá matando, aprisionando ou domando Sexta-Feira. Essas seriam as soluções de cada um para o problema. Não há que se falar em justiça ou racionalidade nessa situação. Em verdade, o animal irracional seria apenas um problema técnico para Crusoé, não moral. Crusoé não tem outra escolha: ou morre ou contém o gorila, seja matando, aprisionando ou domando. Logo, somente se ambas as partes envolvidas no conflito tiverem a capacidade de argumentar, é que estaremos diante de um problema cuja solução pode ser racional. (HOPPE, 1993, p. 385-386)

Portanto, com supedâneo nos fundamentos acima apresentados, Hans Hoppe estabelece os pressupostos éticos da argumentação, ideias normativas que não podem ser negadas sem que se caia em uma contradição performativa. Ademais, ao desenvolver a sua Ética, Hoppe transcende a ética em si, na medida em que não busca exatamente a descrição das condutas permitidas e proibidas, mas sim busca traçar os limites lógicos e argumentativos através dos quais uma ética pode se fundamentar, chegando à conclusão de que a sua Ética Argumentativa (também chamada de Ética Libertária) é a única logicamente defensável.

Em suma, como deduções inescapáveis, a Ética desenvolvida por Hans-Hermann Hoppe estabelece a autopropriedade e o homesteading (apropriação original) como as únicas prescrições que evitam os conflitos sem entrarem em contradição.

A noção de autopropriedade é, pois, a norma pressuposta numa argumentação. Ao participar de uma argumentação, e estar disposto a ouvir o outro e ser convencido ou não por ele, eu explicito que tenho o controle exclusivo do meu próprio corpo e também que o outro argumentador tem o direito de controle exclusivo do corpo dele. Nas palavras de Hans Hoppe:

Portanto, pode-se afirmar que toda vez que uma pessoa alega que alguma afirmação pode ser justificada ela considera, pelo menos implicitamente, a norma seguinte para ser justificada: "Ninguém tem o direito de agredir o corpo de outra pessoa sem permissão e dessa forma delimitar ou restringir o controle de outrem sobre o seu próprio corpo". Esta regra está contida no conceito de justificação enquanto justificação argumentativa. Justificar significa justificar sem ter que depender de coerção. De fato, se é possível formular o contrário dessa regra, ou seja, que "todo mundo tem o direito de agredir outra pessoa sem permissão" (uma regra que, a 
propósito, passaria no teste formal do princípio da universalização!), então é fácil ver que essa regra não é, e nunca poderia ser, defendida numa argumentação. Fazê-lo exigiria pressupor exatamente a validade do oposto disso, ou seja, o supracitado princípio da não-agressão. (HOPPE, 2013, p. 129-130).

Em outras palavras, considerando que o direito de todos os sujeitos com capacidade argumentativa de participarem de uma argumentação é pressuposto em uma justificação sobre normas, o direito de autopropriedade de todos eles também está implícito.

Desse conceito de autopropriedade, portanto, deriva-se o homesteading, ou seja, o direito de primeira apropriação dos bens fornecidos pela natureza, ou também conhecida como apropriação original.

A negação do direito de uso exclusivo e definitivo sobre os meios adquiridos com o primeiro uso irá sempre, necessariamente, entrar em contradição performativa, pois para que uma pessoa possa negar tal direito ela deve: a) ou defender o direito de uma pessoa impedir a outra de utilizar estes meios, ideia que negaria o direito de autopropriedade anteriormente explicado e, por isso, cairia em contradição performativa; b) ou defender que os direitos de uso dos meios adquiridos não são exclusivos, ou que eles não são definitivos, situação essa que também levaria a uma contradição performativa, posto que contraria o próprio objetivo de uma justificação de normas, na medida em que leva a conflitos ao invés de evitá-los.

Por fim, Hans-Hermann Hoppe, salientando a necessidade do elo objetivo apto a tornar visível a apropriação original, explica:

Uma vez que segundo o princípio da não-agressão uma pessoa pode fazer com o seu corpo tudo aquilo que quiser na medida em que, desse modo, ela não agrida o corpo de outra pessoa, essa pessoa poderia usar outros meios escassos, assim como usar o seu próprio corpo, desde que essas outras coisas já não tenham sido apropriadas por alguém e continuem num estado natural sem dono. Enquanto os recursos escassos são visivelmente apropriados - tão logo alguém "mistura o seu trabalho", para usar a frase de John Locke, com esses recursos e há traços objetivos dessa ação - , a propriedade, ou seja, o direito de controle exclusivo, só pode ser adquirida por uma transferência contratual de títulos de propriedade de um proprietário anterior para o atual, e qualquer tentativa de delimitar unilateralmente esse controle exclusivo de proprietários anteriores ou qualquer transformação não solicitada das características físicas dos meios escassos em questão é, numa analogia estrita com as agressões contra os corpos de terceiros, uma ação injustificável. (HOPPE, 2013, p. 130-131).

Portanto, a conclusão inevitável a que chega Hans-Hermann Hoppe é a de que, considerando que toda norma, para que possa ser demonstrada como verdadeira, deve ser justificada através de uma argumentação, qualquer norma que negue aos indivíduos o direito de controle exclusivo dos próprios corpos, assim como o direito de se apropriar de outros meios, será logicamente indefensável, uma vez que qualquer um que assim argumente entrará em contradição performativa. Logo, a única lei logicamente defensável é a Ética Argumentativa Hoppeana (Ética Libertária).

\section{A TRIBUTAÇÃO SOB A ÉTICA HOPPEANA}

Entendida a Ética desenvolvida por Hans-Hermann Hoppe, fica fácil compreender, doravante, o instituto da tributação sob a visão do autor.

A tributação é o ato pelo qual o Estado retira parte do patrimônio dos cidadãos, entregando-a aos cofres públicos (ATALIBA, p. 2014, p. 21). A receita do Estado deriva, na sua esmagadora maioria, 
da tributação, de modo que a folha de pagamento de seus servidores, a manutenção de seus órgãos e a realização de seus programas sociais, por exemplo, dependem da renda levantada com os tributos.

Existe, portanto, uma característica inerente da tributação, que é a compulsoriedade. O cidadão não tem a prerrogativa de escolher ou não pagar o tributo, mas está obrigado a enriquecer o estado mesmo contra a sua vontade. O proprietário de um veículo automotor está obrigado a fazer 0 pagamento ao estado da federação no qual resida do IPVA, tributo esse que é pago anualmente e equivale a uma porcentagem sobre o valor do bem. O mesmo ocorre com o cidadão proprietário da casa em que mora na cidade. Ele deve fazer o pagamento do IPTU anualmente, cujo valor também equivale a uma porcentagem do valor total do imóvel.

Caso o indivíduo não realize o pagamento desses tributos, ele sofrerá uma série de sanções, que vão desde os juros sobre o valor inadimplente até a perda do bem. Para tal coação o Estado se vale da Ação de Execução Fiscal, a fim de compelir o cidadão ao pagamento do tributo até com a possível excussão dos bens do indivíduo.

Em última análise, caso o cidadão ainda relutasse com o pagamento compulsório do tributo e tentasse legitimamente defender seu patrimônio da excussão judicial, ele seria compelido pelo uso da força, ou seja, poderia ser agredido, preso ou talvez sofresse coisas piores (HOPPE, 2013, p. 143) Por isso que o monopólio da força é, por exemplo, tão importante para o Estado. O poder da polícia e do exército é fundamental para assegurar todos os outros poderes do Estado, incluindo o todo poderoso poder de extrair seus rendimentos através da coerção (ROTHBARD, 2010, p. 232).

Levando-se em consideração as noções de direito de propriedade desenvolvidas por Hans-Hermann Hoppe e considerando que o indivíduo dispendeu seu corpo, tempo, energia e outros recursos para amealhar aquele patrimônio, seja através do trabalho direto, seja através de interações contratuais, a renda deles derivada é sua propriedade e somente a ele pertence. Desse modo, qualquer invasão do patrimônio do indivíduo sem o seu consentimento, seria uma injusta agressão praticada pelo Estado.

Ademais, tendo por base a Ética Argumentativa Hoppeana, sabe-se que qualquer "lei" que atente contra a propriedade privada não é logicamente defensável, seja por se contradizer ao legitimar uma violação da autopropriedade, seja por não resolver conflitos, mas criá-los.

Portanto, segundo os ensinamentos de Hans Hoppe, a tributação é antiética, imoral e logicamente indefensável. Atenta contra a natureza humana ao legitimar e sistematizar a agressão.

O mentor de Hoppe, Murray N. Rothbard, bem sintetizou essa questão:

Pois há um poder crucialmente importante inerente à natureza do aparato do estado. Todas as outras pessoas e grupos da sociedade (exceto criminosos conhecidos e esporádicos, como ladrões de banco e assaltantes) obtêm seus rendimentos voluntariamente: ou pela venda de bens e serviços ao público consumidor, ou por doação voluntária (e.g., participação em um clube ou associação, legado ou herança). Somente o estado obtém sua receita através da coerção, através da ameaça da aplicação de terríveis penalidades se o rendimento não for disponibilizado. Esta coerção é conhecida como "imposto", embora, em épocas menos regularizadas, ela fosse frequentemente chamada de "tributo". Imposto é roubo, de maneira pura e simples, apesar de ser um roubo numa escala grande e colossal a qual nenhum criminoso popular pode jamais sonhar em igualar. Ele é uma tomada compulsória da propriedade dos habitantes ou súditos do estado. 
Seria um exercício instrutivo para o leitor cético tentar formular uma definição de imposto que também não incluísse roubo. Assim como o ladrão, o estado exige dinheiro com o equivalente à mira de um revólver; se o pagador de impostos se recusar a pagar, seus bens são confiscados através da força, e, se ele resistir a esta pilhagem, ele será preso ou levará um tiro se continuar a resistir. (ROTHBARD, 2010, p. 232-233).

\section{E prossegue:}

Se, então, o imposto é compulsório e, portanto, indissociável de roubo, logo o estado, que subsiste pelos impostos, é uma enorme organização criminosa muito mais impiedosa e bem-sucedida do que qualquer máfia "privada" da história. Além disto, ele deveria ser considerado criminoso não apenas de acordo com a teoria de direitos de propriedade e de crime mostrada neste livro, mas mesmo de acordo com o entendimento comum da humanidade, que sempre considera que o roubo é um crime (ROTHBARD, 2010, p. 237).

Rothbard ainda ressalta que não é porque a tributação (ou nas palavras dele, roubo) foi "tolerada" pela maioria dos cidadãos, mediante uma votação, que ela deixa de ser uma violação de propriedade. O assassinato sempre será assassinato e o roubo sempre será roubo, independentemente se praticado por um indivíduo ou um grupo deles. O fato de uma maioria apoiar ou tolerar o roubo não diminui a essência criminal do ato ou a sua grave injustiça (ROTHBARD, 2010, p. 235).

Sendo assim, Murray Rothbard concluiu dizendo que o Estado não passa de uma organização criminosa que subsiste através da institucionalização do roubo, pilhagem essa praticada em grande escala e que conta com a proteção de certos grupos de intelectuais e formadores de opinião que são recompensados, em certa medida, com a espoliação (ROTHBARD, 2010, p. 243). Há, portanto, a perpetuação do crime e uma constante propaganda para tolerar e amenizar essa situação.

A Ética desenvolvida por Hoppe, ademais, conduz inevitavelmente às conclusões a que chegou seu mentor, ou seja, de que a tributação é antiética, imoral e logicamente indefensável, de modo que o Estado, por depender necessariamente da tributação, também o é.

Ao equiparar a tributação ao roubo, Hoppe também ensina que a invasão patrimonial praticada pelo Estado é ainda pior do que o roubo esporádico em si, uma vez na tributação o indivíduo sequer pode tentar se defender:

As coisas, entretanto, mudam radicalmente - comprometendo permanentemente o processo de civilização - sempre que as violações dos direitos de propriedade assumem a forma de interferência governamental. A marca distintiva das violações governamentais do direito de propriedade privada é que, ao contrário das atividades criminosas, elas são consideradas legítimas não apenas pelos agentes do governo que se dedicam a elas, mas também pelo público em geral $(e$, em casos raros, até mesmo pela vítima). Assim, nessa situação, a vítima não pode legitimamente defender-se de tais violações.

A instituição de um imposto governamental sobre os bens ou os rendimentos viola os direitos de propriedade do produtor tanto quanto o roubo. Em ambos os casos, a oferta de bens do apropriador/produtor é diminuída contra a sua vontade e sem o seu consentimento. A moeda governamental - i.e., a criação de "liquidez" - não menos significa uma expropriação fraudulenta dos donos de propriedade do que as operações de uma gangue criminosa de falsificadores. Ademais, as regulações do governo acerca do que um proprietário pode ou não pode fazer com a sua propriedade - para além da regra de que ninguém pode causar danos físicos à propriedade dos outros e de que todas as trocas (comércio) uns com os outros devem ser voluntárias e contratuais - implicam uma "apropriação" da propriedade de alguém da mesma forma como o 
fazem os atos de extorsão, de roubo ou de destruição. Mas a tributação, a criação de "liquidez" perpetrada pelo governo e as regulações governamentais, ao contrário dos seus homólogos penais, são consideradas legítimas; e a vítima da interferência do governo, ao contrário da vítima de um crime, não tem o direito à defesa física e à proteção da sua propriedade. (HOPPE, 2014, p. 43-44).

Nessa esteira, segundo Hoppe, o governo não mais é do que uma agência que se engaja em violações contínuas e institucionalizadas dos direitos de propriedade; uma agência que se dedica à exploração - sob a forma de expropriação, tributação e regulação - dos donos de propriedades privadas. (HOPPE, 2014, p. 75)

Resta claro, portanto, que a tributação viola consistentemente a Ética Hoppeana e, por consequência, o direito natural à propriedade privada. Não obstante, Hoppe considera ainda que umas das causas desse flagelo que é tributação, notadamente a sua tolerância com quantias cada vez maiores, diz respeito a um declínio intelectual e moral da população. A espoliação estatal resulta, outrossim, em outros graves problemas, tais como o aumento da preferência temporal das pessoas, a diminuição da riqueza geral e da qualidade de vida da sociedade, e até mesmo num declínio civilizatório.

Portanto, considerando o exposto, toda pessoa, sendo proprietária do seu próprio corpo físico, tem o direito de fazer o que bem entender com ele e suas propriedades, desde que não agrida outras pessoas. A consequência necessária dessa reflexão é que todas as trocas intersubjetivas devem ser voluntárias (contratuais), rejeitando-se qualquer tipo de coerção injusta sobre os indivíduos. (HOPPE, 2014, p. 164).

Por fim, superada essa questão e considerando que a tributação não traz consequências apenas éticas, doravante analisar-se-á as consequências econômicas da tributação, tendo como base a metodologia praxeológica da Escola Austríaca de Economia, corrente econômica da qual HansHermann Hoppe faz parte.

\section{A CIÊNCIA ECONÔMICA E O MÉTODO AUSTRÍACO}

Hans-Hermann Hoppe, como adepto da Escola Austríaca de Economia, identifica a ciência econômica como sendo a ciência da ação humana. Portanto, a metodologia utilizada para compreender a ciência econômica é a praxeologia, desenvolvida por Ludwing von Mises.

Mises, através de seu magnum opus "Ação Humana: Um Tratado de Economia", ensina que a ciência econômica não é empírica, ou seja, não deriva da experiência. A economia, na verdade, é apriorística, muito mais relacionada com a lógica do que qualquer outra ciência. (MISES, 2010, p. 59).

Logo, nessa visão misesiana, a economia tem como ponto de partida o axioma de que o ser humano age, de modo que a partir dessa premissa considerada necessariamente evidente e verdadeira, deduz-se vários outros conceitos e análises econômicas.

Ser uma ciência a priori, cujas proposições podem receber uma rigorosa justificação lógica, é a principal característica que separa a Escola Austríaca de Economia das demais escolas de pensamento econômico. Todas as outras Escolas concebem a ciência econômica como empírica, tal como outras ciências que requerem o desenvolvimento de uma hipótese e a constante verificação através da experiência. (HOPPE, 2010, p. 10) 
Em verdade, embora com termos distintos, a praxeologia como metodologia para estudar a economia já era comum antes mesmo de Mises. Podia ser observada nos escritos dos economistas Jean-Baptiste Say (1767-1832), Nassau William Senior (1790-1864), John Elliott Cairnes (1823-1875), Carl Menger (1840-1921) e Eugen von Böhm-Bawerk (1851-1914), por exemplo.

Nessa esteira, como bem apontam os "austríacos", proposições como: a) sempre que duas pessoas se envolvem numa troca voluntária, ambas devem esperar se beneficiar através dela (elas têm ordens de preferência inversas para os bens e serviços trocados, ou seja, ambas as pessoas valorizam mais o que recebem do que o que entregam); b) sempre que uma troca não é voluntária e ocorre por meio da coerção, uma parte se beneficia às custas da outra; c) sempre que leis de salário mínimo são impostas obrigando os salários a serem maiores do que os salários existentes no mercado, desemprego involuntário será a consequência; não necessitam de observação empírica para a sua comprovação. Eram verdadeiras antigamente, são verdadeiras agora e continuarão sendo no futuro.

Se João está disposto a pagar trinta reais por um prato de comida no restaurante de César, quer dizer que João dá mais valor para o prato de comida que receberá do que para os seus trinta reais, sendo que César valoriza mais o dinheiro que receberá do que a refeição que entregará. Caso contrário, se a troca não fosse voluntária, significaria que uma das partes valoriza mais fazer outra coisa com o produto que entregará do que participar daquela relação, de modo que uma se beneficia em detrimento da outra. Se um salário mínimo é estabelecido, independentemente das intenções da lei, o que a norma diz é que quem não produz (agrega valor) o valor estabelecido no salário mínimo, não poderá ser contratado nunca, sendo que quem será mais prejudicado com essa lei serão justamente quem se pretende ajudar (HOPPE, 2010, p. 14-15). É por isso, ademais, que uma lei não deve ser analisada por suas intenções, mas pelas suas consequências.

Hans-Hermann Hoppe se vale, ainda, da analogia para melhor exemplificar o fato de a ciência econômica não ser empírica. É como se alguém, querendo comprovar o teorema de Pitágoras, quisesse medir todos os lados e ângulos de todos os triângulos retângulos para verificar a veracidade da proposição. Fazer isso tanto no teorema de Pitágoras, quanto no estudo econômico em si, seria um claro sinal de confusão intelectual. (HOPPE, 2010, p. 15-16)

É importante lembrar também que a praxeologia misesiana foi claramente influenciada pelos ensinamentos epistemológicos de Immanuel Kant (1724-1804). Considerando as limitações do presente trabalho, bem como que o escopo deste não é o estudo da epistemologia kantiana, basta ao leitor saber que Mises, assim como Kant, afirmava que existem proposições sintéticas a priori, ou seja, proposições que não podem ser definidas como verdadeiras ou falsas apenas utilizando os meios da lógica, mas que também não são necessárias observações posteriores.

Partindo disso, Mises ensina que toda a dedução oriunda do axioma da ação humana, contanto que no processo não contenha nenhum erro, as conclusões a que ela chega também serão a priori, uma vez que suas validades remetem-se, em última análise, àquele axioma incontestável.

Outras características fundamentais da metodologia austríaca são o individualismo metodológico e a noção de que o conhecimento (informação) é disperso. Ou seja, o estudo da economia não deve partir de conglomerados econômicos, mas sim do indivíduo criativo (empreendedor), além de que não há uma plenitude do conhecimento pelos seres humanos, uma vez que a informação está dispersa desigualmente na sociedade e em constante mudança. 
No tocante à informação dispersa na sociedade, a Escola Austríaca de Economia, mais precisamente por meio do economista Friedrich August von Hayek (1899-1992), ensinou que cada indivíduo detém uma parcela muito pequena do conhecimento das coisas, bem como que a informação dos bens desejados pelas pessoas está em constante mudança, de modo que não é possível haver um planejamento central da economia. Não tem como um seleto grupo de indivíduos ordenar a economia de maneira centralizada, posto que não é possível ter informações suficientes para alocar os recursos de maneira eficiente. Portanto, a intervenção governamental na economia será sempre ineficiente e destrutiva para a sociedade.

Sendo assim, o método apriorístico-dedutivo, o individualismo metodológico e a noção de que o conhecimento (informação) sobre as coisas nunca é perfeito, são os alicerces da metodologia austríaca para análise econômica.

Em que pese outras características adjacentes da Escola Austríaca de Economia, como a noção de que a economia não possui um equilíbrio perfeito, mas tende ao equilíbrio; e a noção de que não há distinção entre micro e macro economia, os pilares principais dessa escola de pensamento econômico são os apontados acima.

Portanto, Hoppe, endossando as ideias de Ludwing von Mises, também analisa a economia a partir dessa metodologia (praxeologia), sendo que os conceitos econômicos desenvolvidos a partir dessa reflexão podem ser validados sem a necessidade da experiência.

Por fim, antes de ingressarmos no capítulo seguinte e analisar mais profundamente as consequências econômicas da tributação, cumpre mencionar a lição de Hans-Hermann Hoppe sobre alguns exemplos de teorias a priori deduzidas a partir do estudo da praxeologia:

Mais importante ainda: exemplos de teoria a priori também são abundantes nas áreas das ciências sociais (especialmente nas áreas da economia política e da filosofia): A ação humana é o propositado esforço de um agente com a finalidade de concretizar, com o uso de meios escassos, objetivos escolhidos. Ninguém pode propositalmente não agir. Toda ação tem como propósito melhorar o bem-estar subjetivo do agente acima do estado em que, caso contrário, ele estaria. Uma quantidade maior de um bem é mais valorizada do que uma quantidade menor desse mesmo bem. A satisfação mais cedo é preferida à satisfação mais tarde. A produção deve preceder o consumo. $O$ que é consumido agora não pode ser consumido novamente no futuro. Se o preço de um bem é diminuído, a mesma quantidade ou uma quantidade maior será comprada do que no caso contrário. Se os preços são fixados abaixo do nível de mercado (preços máximos), a escassez duradoura será a consequência. Sem a propriedade privada dos meios de produção, não é possível haver preços para esses fatores; e, sem preços, a sua contabilidade de custos é impossível. Os tributos são uma imposição sobre os produtores e/ou sobre os proprietários de riqueza, reduzindo a produção e/ou a riqueza abaixo do nível em que, no caso contrário, elas poderiam estar. O conflito interpessoal é possível apenas se - e na medida em que - as coisas são escassas. Nenhuma coisa ou parte de uma coisa pode ser detida exclusivamente por mais de uma pessoa ao mesmo tempo. A democracia (governo da maioria) é incompatível com a propriedade privada (propriedade particular e autonomia individual). Não há forma de tributação que possa ser uniforme (igual), mas toda tributação envolve a criação de duas classes distintas e desiguais: pagadores de impostos versus consumidores e recebedores de impostos. Bens (propriedades) e títulos de propriedade são entidades distintas, e um aumento dos últimos sem um correspondente aumento dos primeiros não eleva a riqueza social, mas conduz a uma redistribuição da riqueza existente. (HOPPE, 2014, p. 22-23). 


\section{CONSEQUÊNCIAS ECONÔMICAS DA TRIBUTAÇÃO}

Levando-se em consideração tudo o que fora exposto, tanto pela Ética Argumentativa Hoppeana, quanto pela metodologia da Escola Austríaca de Economia, é possível notar que Hans-Hermann Hoppe é um ferrenho crítico da intervenção estatal na vida dos indivíduos.

Pelo aspecto ético já foi explicado que a espoliação praticada pelo Estado é antiética e imoral, porque atenta contra os direitos naturais do ser humano e não pode ser justificada logicamente. Todavia, na seara econômica a tributação não leva melhor sorte.

Além de o Estado necessitar da tributação para sustentar todo o seu aparato, ele também a utiliza como forma de redistribuição de renda. Nesse sentido, o que Hoppe nos mostra é que isso é extremamente prejudicial, uma vez que gera um processo de destruição de riqueza que piora a qualidade de vida de todos.

Na verdade, o argumento utilitarista, ou seja, de que se deveria buscar o meio mais economicamente eficiente de arranjar os recursos, não deveria nem sequer ser levado em consideração para refutar a tributação. Na visão hoppeana, o argumento contra a tributação deveria se encerrar no âmbito da ética. Defender a tributação pelos seus aspectos econômicos seria a mesma coisa que defender a escravidão por trazer mais eficiência econômica na colheita de laranja. Da mesma forma que a escravidão é errada em si, independentemente de qualquer questão de economia, a tributação também deveria ser. Entretanto, como bem demonstrado por Hoppe, a tributação também é condenável no âmbito econômico, posto que resulta em destruição de riqueza e, consequentemente, numa diminuição da qualidade de vida das pessoas.

Primeiramente, é importante entender a preferência temporal. Nesse sentido, Hoppe explica que o ser humano, ao agir, sempre visa sair de um estado de menor satisfação para um estado de maior satisfação, de modo que ele sempre demonstra uma preferência por mais bens do que menos. Ademais, sempre é considerado o momento futuro no qual os fins serão atingidos, ou seja, leva-se em consideração o tempo necessário para atingir o seu objetivo e a durabilidade deste. Logo, o ser humano sempre demonstra uma preferência por bens presentes a bens futuros e por bens mais duráveis a bens menos duráveis. Este é, pois, o fenômeno da preferência temporal. Considerando também que o tempo é sempre escasso e que o ser humano sempre deve consumir algo enquanto estiver vivo, então, ceteris paribus ${ }^{5}$, os bens presentes deverão ser sempre mais valorizados do que os bens futuros. Com efeito, se não houvesse a limitação da preferência temporal agindo sobre o ser humano, de modo que a única restrição que operasse sobre ele fosse preferir mais ao invés de menos bens, ele sempre escolheria os processos de produção mais eficientes, ou seja, que fornecessem um maior retorno com menos custos, independentemente do tempo necessário para colher os resultados. Ele sempre pouparia e nunca consumiria. Sendo assim, trazendo para o exemplo de Robinson Crusoé, o marinheiro não começaria fazendo primeiro uma rede de pesca, mas construiria direto o barco, haja vista que esse método seria economicamente mais eficiente para a captura dos peixes. Portanto, a preferência temporal é o que restringe a quantidade de poupança e investimento. (HOPPE, 2014, p. 31-32)

Partindo disso, Hoppe ensina que quanto maior a preferência temporal de uma sociedade, maior será o gasto imediato e menor será a poupança, ao passo que quanto menor a preferência temporal, mais

\footnotetext{
${ }^{5}$ Expressão em latim que significa "mantidas inalteradas todas as outras coisas" ou "todo o mais constante".
} 
poupança será realizada, o que permitirá o empréstimo para bens de capital mais complexos, de modo que mais rápido será o alongamento da estrutura de produção indireta. $O$ aumento na acumulação de bens de capital e o alongamento da estrutura de produção indireta aumentará também a produtividade marginal da mão-de-obra e os salários e/ou empregos, o que, por consequência, gerará um aumento no padrão de vida geral.

Porém, existem vários fatores que influenciam na preferência temporal, podendo ser externos, biológicos, pessoais e sociais/institucionais. Externos são os fatores que ocorrem no ambiente físico em que o agente vive, fatores esses que não podem ser controlados diretamente ou indiretamente pelo agente, como por exemplo uma forte e destruidora tempestade. Fatores biológicos, apesar de estarem em certa medida sob o alcance do agente, a longo prazo eles também são inevitáveis, como por exemplo a evolução da idade e maturidade do ser humano que culmina com a morte. Os fatores pessoais podem ser entendidos como aqueles que derivam da subjetividade e personalidade do indivíduo, como o sujeito ter passado por momentos de dificuldade na infância. Por fim, os fatores sociais/institucionais podem ser entendidos como aqueles oriundos da sociedade em que o agente vive, como por exemplo a criminalidade. (HOPPE, 2014, p. 34-35)

Todos esses fatores mencionados acima podem aumentar ou diminuir a preferência temporal das pessoas. A título de exemplo, a preferência temporal de uma pessoa que se aproxima da morte tende a aumentar, porque lhe resta pouco tempo para usufruir daqueles prazeres mundanos que a vida oferece; entretanto, a preferência temporal dessa pessoa tenderá a diminuir, ainda que na tenra idade, na medida em que ela tenha filhos para quem deseje deixar uma certa quantidade de patrimônio a fim de permitir uma vida menos sofrida. Já a criminalidade tem o condão de aumentar a preferência temporal, uma vez que o cidadão que acumula capital é desestimulado a assim prosseguir toda vez que tem parte de seu patrimônio subtraído por um meliante.

No entanto, uma vez que o grau de preferência temporal seja baixo o suficiente a fim de permitir a formação de poupança, de capital e de bens de consumo duráveis, inicia-se um movimento de tendência à queda da taxa de preferência temporal e, consequentemente, um processo de civilização. (HOPPE, 2014, p. 36) Em outras palavras, o poupador/investidor inicia um processo de desenvolvimento e amadurecimento da economia, ocorrendo assim uma transição da infância à fase adulta e da barbárie à civilização (HOPPE, 2014, p. 37).

Ocorre que a tributação praticada pelo Estado - entendida como a invasão na propriedade privada do indivíduo - diminuirá a preferência temporal dos cidadãos. Nesse sentido a tributação funciona da mesma forma que o crime. Em verdade, Hoppe esclarece que as violações dos direitos de propriedade podem se dar apenas dessas duas formas, a saber, crimes propriamente ditos e/ou interferências governamentais (HOPPE, 2014, p. 41).

Entretanto, no tocante ao "crime comum", Hoppe esclarece que ele é considerado ilegítimo e/ou injusto por todos - muitas vezes até pelo próprio criminoso -, de modo que há o entendimento na sociedade de que a vítima tem o direito de se defender daquela agressão, bem como exigir uma compensação do agressor. Ademais, o crime tem dois impactos marcantes, na medida em que, por um lado, diminui a oferta de bens da vítima, elevando a taxa de preferência temporal desta, e, por outro, promove a realocação dos recursos (tanto da vítima, quanto das demais pessoas da região) para outras atividades, uma vez que haverá um aumento nos investimentos em segurança (p. e. comprando armas, construindo muros e cercas, instalando sistemas de alarme e monitoramento, contratando empresas de segurança e seguros etc.). Portanto, a existência de atividades criminosas 
implica num retrocesso no processo que conduz à queda da preferência temporal da sociedade, já que, além de diminuir o patrimônio das vítimas, promovem gastos que seriam vistos como desnecessários caso não houvesse crimes (HOPPE, 2014, p. 42).

Não obstante, os crimes são temporários e não sistemáticos, ou seja, eles são intermitentes, de modo que o assaltante desaparece da cena com o seu produto do roubo, deixando a vítima sozinha, livre e "em paz". Além disso, como dito acima, medidas preventivas com segurança e de legítima defesa podem ser adotadas contra os crimes e aperfeiçoadas com o tempo, de modo a permitir que a vítima saia bem-sucedida contra a investida criminosa. Entretanto, as violações de propriedade privada praticadas pelo Estado, por serem "legítimas", são constantes. Após a espoliação, o governo não desaparece na clandestinidade, mas permanece ao redor; e a vítima não pode se armar para tentar se defender contra ele, mas permanece indefesa (HOPPE, 2014, p. 43-44).

Portanto, a conclusão a que Hans-Hermann Hoppe chega é de que a tributação, interferindo diretamente na propriedade privada dos indivíduos, aumentará a taxa de preferência temporal daquela sociedade e, consequentemente, haverá menos poupança, menos investimentos, até o declínio da civilização para a barbárie. Se a sociedade se desenvolve e enriquece é apesar dos tributos e não por causa deles.

De outro giro, não se pode olvidar da questão que diz respeito à alocação do recurso que foi obtido com a tributação. Como dito acima, o conhecimento está disperso na sociedade, de modo que é impossível que um grupo de pessoas (Estado) aloque racionalmente os recursos. Qualquer alocação de recursos escassos que não seja voluntária, será uma destruição de riqueza. O Estado não tem como saber onde seria melhor alocar os recursos e ainda que acerte, será por coincidência. Se as pessoas querem determinado produto/serviço elas o contratariam voluntariamente, ao passo que se aquele produto/serviço foi "comercializado" por meio de coação, quer dizer que as pessoas não prefeririam aquilo antes de qualquer outra coisa. Logo, o planejamento central da economia, por não ser possível deter toda a informação (conhecimento) dispersa na sociedade, sempre destruirá riqueza com alocações econômicas ineficientes.

Ademais, a falta de informação para alocação dos recursos pode ser analisada em conjunto com ensinamentos de Fréderic Bastiat que intitula um de seus livros: "O Que Se Vê e o Que Não Se Vê". Em outras palavras, esquece-se das consequências de longo prazo da tributação, e pensa-se apenas nas imediatas. É visível uma ponte que foi construída com base na receita oriunda dos tributos. Afirma-se ainda: se não fosse os tributos, não seria possível a construção dessa ponte para escoar a produção de milho. Entretanto, o que não se vê é o que deixou de ser produzido, a mão-de-obra que foi dispensada ou deixou de ser contratada e o dinheiro que deixou de ser poupado (o que diminuiria a taxa de juros, por exemplo) devido àquela tributação. Em suma, não se analisa os prejuízos advindos daquela espoliação legal.

Outro ponto importante explicado por Hans-Hermann Hoppe é o que foi melhor abordado em sua obra "Uma Teoria do Socialismo e do Capitalismo". Nessa obra, cujo enfoque principal é a consequência econômica desses dois sistemas, Hoppe define como socialismo qualquer interferência estatal na economia, variando de acordo com o grau de interferência, e capitalismo como um sistema livre de coerção e interferência estatal, no qual a propriedade privada é respeitada e o único meio de troca possível é a contratual, ou seja, livre mercado. Quanto aos tipos de socialismo, Hoppe aponta três, que variam, como dito, de acordo com o grau de interferência do Estado. A nacionalização completa dos meios de produção, ou a quase completa abolição da propriedade privada é o socialismo 
ao estilo "russo". Nesse tipo de intervenção Hoppe aponta três piores consequências econômicas: a queda relativa na taxa de investimentos (taxa de formação de capital); o desperdício dos meios de produção com uma elevação dos custos; e que esse sistema provoca o empobrecimento relativo da população, ou seja, uma queda no padrão de vida geral. ${ }^{6}$ O desastre da União Soviética é a prova da destruição que esse sistema é capaz de causar. O outro tipo de socialismo é o "socialismo ao estilo "social-democrata". Nesse tipo de intervenção, que é o que a maioria dos países adota hoje, como o próprio Brasil, não há uma proibição total da propriedade privada, sendo que ela é até tolerada, porém o proprietário tem de pagar sempre uma quantia para o Estado relativa ao bem que possui. No tocante aos bens de produção, os impostos retiram parte da renda da produção do proprietário, de modo que o dono não pode ficar com cem por cento do que lhe é de direito. Além disso, outros serviços continuam como monopólio estatal, tais como banco central, polícia e justiça. Em resumo, esse tipo de socialismo advoga pela expropriação parcial da propriedade privada, através da tributação nos bens de produção, nos serviços em si, nos imóveis, na herança etc.. ${ }^{7} 0$ último tipo de intervencionismo apontado por Hoppe é o socialismo do "conservadorismo". Esse tipo de socialismo chega a ser muito parecido com o "social-democrata", pois não torna ilegal a propriedade privada e continua tributando-a. Porém, em que pese haver uma certa diminuição na tributação sobre os indivíduos, há controle de preços, regulações e controle de comportamento no mercado. ${ }^{8}$

Os três tipos de intervencionismo apontados acima são destrutivos economicamente, em maior ou menor grau de acordo com o tamanho da intervenção. Todavia, utilizaremos como base para a reflexão a seguir o socialismo ao estilo "social-democrata", que é o que existe no Brasil hoje e que está mais ligado à tributação massiva.

Nesse tocante, Hans-Hermann Hoppe apresenta outro ponto negativo da tributação, o qual leva à mesma conclusão acima, uma queda no padrão geral de vida:

Qual é o resultado econômico da introdução de tributos sobre a renda ou sobre as vendas onde antes não havia tributação, ou do aumento para um novo patamar do nível de tributação já existente? Ao responder esta questão, eu irei, além disso, ignorar as complicações que resultam das diferentes formas possíveis de redistribuir o dinheiro tributado para diferentes indivíduos ou grupos de indivíduos - o que será discutido posteriormente neste capítulo. Neste momento, consideraremos apenas o fato geral, verdadeiro, por definição, para todos os sistemas redistributivos, de que qualquer redistribuição do dinheiro tributado é uma transferência de produtores de renda monetária e recebedores de dinheiro por meio de contratos para pessoas na qualidade de não-produtoras e de não-recebedoras de renda monetária por contratos. Introduzir ou elevar a tributação reduz para o produtor o fluxo da renda monetária da produção e o aumentar para os não-produtores e não-contratantes. Tal decisão altera os custos relativos de produção para retorno monetário versus os custos relativos de não-produção e produção para retornos não-monetários. Consequentemente, na medida em que essa mudança é percebida pelas pessoas, elas irão cada vez mais consumir vagarosamente e/ou produzir com a finalidade de permutar, e reduzir, simultaneamente, seus esforços produtivos para obter recompensas monetárias. De qualquer maneira, cairá a produção de bens a serem adquiridos com dinheiro, o que significa dizer que o poder de compra diminui e, consequentemente, ocorre um declínio no padrão geral de vida. (HOPPE, 2013, p. 56).

\footnotetext{
${ }^{6}$ Ver o capítulo três de Uma Teoria do Socialismo e do Capitalismo. $2^{a}$ Ed. São Paulo: Instituto Ludwing von Mises Brasil, 2013.

7 Ver o capítulo quatro de Uma Teoria do Socialismo e do Capitalismo. $2^{\text {a }}$ Ed. São Paulo: Instituto Ludwing von Mises Brasil, 2013.

${ }^{8}$ Ver o capítulo cinco de Uma Teoria do Socialismo e do Capitalismo. $2^{\mathrm{a}}$ Ed. São Paulo: Instituto Ludwing von Mises Brasil, 2013.
} 
Hoppe aponta, ainda, outro problema da tributação, mais precisamente o que reside em um sistema que se sustenta com essa espoliação. Como os produtores terão parte de seu patrimônio confiscado para entregar para não produtores, o incentivo será cada vez maior para se mudar de uma cultura produtiva para uma cultura preguiçosa e hedonista. Haverá, também, uma disputa para fazer parte da casta recebedora dos impostos. O cidadão pode fazer parte da parcela da sociedade que paga impostos (iniciativa privada) ou da casta que recebe impostos (servidores públicos). Sendo assim, um incentivo é criado para que pessoas abandonem a iniciativa privada e migrem para o funcionalismo estatal, diminuindo ainda mais a produção de riqueza, situação essa que inicia um processo em direção ao empobrecimento da sociedade.

Por fim, cabe abordar um outro tipo de tributo do qual os Estados podem lançar mão para aumentar o seu poderio econômico, que é mais conhecido como inflação. A inflação, segundo a Escola Austríaca de Economia, é a expansão da base monetária, que traz como consequência a diminuição do poder de compra daquela moeda. Em verdade, quando se aumenta a base monetária, existe mais dinheiro na economia para a mesma quantidade de bens. Consequentemente, com uma mesma unidade monetária comprando menos bens, há uma queda progressiva no poder de compra da unidade monetária e a correspondente elevação dos preços. Portanto, o aumento dos preços é uma consequência da inflação e não a inflação em si. (MISES, 2009, p. 61).

A inflação, ademais, passa a ser uma importante aliada do governo como forma de tributar. A moeda fiduciária, por sua vez, é o instrumento para isso. Como o Estado, através do seu Banco Central, detém o poder de criação de nova moeda, sem lastro algum, ele detém o poder de aumentar o seu poderio econômico às custas de toda a população. Com a impressão de nova moeda, os primeiros recebedores serão beneficiados, pois terão mais dinheiro e conseguirão comprar os bens pelos mesmos preços que estavam antes da criação do dinheiro novo. Todavia, conforme esse dinheiro novo começa a percorrer a cadeia de produção, haverá um aumento nos preços, de modo que os últimos recebedores desse dinheiro - que costumam ser as pessoas mais pobres da sociedade - são prejudicadas, uma vez que elas verão os preços dos produtos nas prateleiras aumentarem sem ter recebido o dinheiro. Essa cadeia de acontecimentos, ademais, é conhecida como "efeito Cantillon" (IORIO, on line). Logo, a inflação é uma forma travestida de tributar, através da qual os últimos recebedores pagam a conta para os primeiros recebedores terem mais poder econômico.

E por que os governos se valem tanto da inflação? Porque a inflação, ao contrário do aumento de impostos, não é percebida como culpa exclusiva do governo. O cidadão comum geralmente imputa a culpa pelo aumento dos preços ao dono do mercado e não à política creditícia expansionista. Em outras palavras, o governo, para arcar com os seus déficits milionários, poderia propor a criação de novos impostos, porém, essa medida é impopular, na medida em que fica claro para o cidadão que ele terá que dar mais dinheiro para sustentar o Estado e sua irresponsabilidade financeira. Sendo assim, o governo, sem nada mencionar ao cidadão, expande a sua base monetária e atinge a sua meta de pagar a conta. Essa farra creditícia, no entanto, será paga pelo cidadão através da inflação.

É por isso, portanto, que governos optam pela inflação no lugar de impostos. Nas palavras de Ludwing von Mises:

Sempre há, sem dúvida, pessoas que percebem o que está ocorrendo mais cedo que as demais e, então, promovem a inflação. Seus lucros excepcionais decorrem do fato de que haverá sempre desigualdade no processo inflacionário. O governo pode considerar que, como método de arrecadar fundos, a inflação é melhor que a tributação: esta é sempre impopular e de difícil execução. Em muitas nações grandes 
e ricas, os legisladores muitas vezes discutiram, por meses a fio, várias modalidades de novos impostos, tornados necessários em decorrência de um aumento de gastos decidido pelo parlamento. Após discutir inúmeros métodos de angariar dinheiro por meio da tributação, finalmente chegaram à conclusão de que talvez o melhor fosse obtê-lo através da inflação.

É evidente que a palavra "inflação" não era pronunciada. Um político no poder, ao recorrer à inflação, não declara: "Vou adotar a inflação como método." Os procedimentos técnicos empregados na produção da inflação são tão complexos, que o cidadão comum não percebe onde ela teve início. Uma das maiores inflações da história, a que teve lugar no Reich alemão após a Primeira Guerra Mundial, não teve seu pico durante a guerra. Foram os níveis a que chegou no pós-guerra que ocasionaram a catástrofe. O governo não anunciou: "Vamos lançar mão da inflação". Simplesmente tomou dinheiro emprestado, indiretamente, do banco central. Não Ihe competia perguntar como o banco central reuniria e liberaria aquela soma. $\mathrm{E}$ o banco central simplesmente imprimiu-a.

Hoje, as técnicas de produção da inflação têm como complicadores a existência da moeda fiduciária. Isso envolve uma outra técnica, mas o efeito é o mesmo. Com uma penada, o governo cria papel-moeda sem lastro, aumentando assim o volume de moeda e de crédito. Basta-lhe emitir a ordem, e lá está o dinheiro sem lastro. 0 governo não se aflige diante do fato de que algumas pessoas sofrerão perdas; a iminente elevação dos preços não o perturba. Os legisladores proclamam: "Esse sistema é magnífico!". Mas esse magnífico sistema tem um defeito básico: dura pouco. Se a inflação pudesse perdurar indefinidamente, não haveria por que criticar os governos por promoverem-na, mas o único fato bem estabelecido acerca desse fenômeno é que, mais cedo ou mais tarde, ele chega inevitavelmente ao fim. (MISES, 2009, p. 66-67).

Mises encerra fornecendo-nos o exemplo catastrófico do meio circulante que houve na Alemanha em 1923. Em 1914 o dólar equivalia a quatro marcos e vinte pfennings, sendo que em 1923, nove anos depois, o dólar correspondia a 4,2 trilhões de marcos (MISES, 2009, p. 66-67). Ou seja, a moeda alemã já não valia coisa alguma.

Talvez reste uma pergunta na cabeça do leitor nesse momento: como pode uma moeda fiduciária que geralmente possuem altas taxas de inflação - ainda continuar sendo utilizada? A resposta é simples: porque existe uma lei de curso forçado que obriga o seu uso.

Portanto, já bem expostas as consequências devastadoras que a tributação pode causar em uma sociedade, sob uma perspectiva hoppeana (e austríaca), vale mencionar um trecho escrito por HansHermann Hoppe que, apesar de ser uma crítica direta à democracia, sintetiza o exposto neste trabalho de que a tributação não é tolerável nem eticamente, nem economicamente:

Mais importante ainda: é preciso que fique claro - mais uma vez - que a ideia da democracia é imoral e não econômica. No tocante ao status moral do governo da maioria, deve ser ressaltado que ela permite que $A$ e $B$ se unam para roubar $C$, que $C$ e $A$, por sua vez, se juntem para roubar $B$ e que, em seguida, $B$ e $C$ conspirem contra $A$ - e assim por diante. Isso não é justiça, mas sim um escândalo moral; e, ao invés de o regime democrático e os seus defensores serem tratados com respeito, eles devem ser tratados com desprezo e ridicularizados como fraudes morais. (HOPPE, 2014, p. 138). 


\section{CONSIDERAÇÕES FINAIS}

Hans-Hermann Hoppe apresenta em suas obras uma defesa rigorosa acerca do direito de propriedade privada, entendido como direito natural inerente a todo ser humano. Sua Ética Argumentativa é a prova disso. Limitando a ética dentro das formulações lógicas da argumentação, Hoppe rechaça peremptoriamente qualquer tolerância com uma noção de agressão.

Como pôde ser observado no presente artigo, Hans Hoppe prova que a tributação é imoral, eticamente indefensável e atenta contra a natureza do ser humano. A espoliação legal não pode ser justificada logicamente no curso da argumentação, de modo que quem advogue a seu favor, cairá inevitavelmente em contradição performática.

Não obstante, além de rechaçar a tributação eticamente, Hoppe demonstra que economicamente ela conduz num empobrecimento geral da população. A consequência última disso é, conforme demonstrado, a condução da sociedade rumo a um processo descivilizatório.

O Estado, que deveria supostamente nos proteger, institucionaliza o crime através da violação sistémica da propriedade privada, e o pior, deixa-nos indefesos. Ele viola consistentemente a propriedade dos seus cidadãos, sob o argumento de que a defende. Ele subverte completamente a noção de caridade para uma falsa filantropia. Ele sujeita os indivíduos às suas determinações arbitrárias e invasivas. Ao invés de nos preservar, ele nos empobrece, destrói nossas famílias, as organizações locais e a moralidade. A responsabilidade individual e a noção de justiça são pervertidas, e consequentemente, há cada vez mais aberrações morais e econômicas.

É sabido, no entanto, que existem várias outras correntes de pensamento sobre o assunto e que o tema não se esgota aqui, porém, buscou-se no presente trabalho expor a visão não ortodoxa do tema, ou melhor dizendo, pouco estudada e comentada nos ambientes acadêmicos, mas que, sem dúvida, engrandece o debate com críticas fundamentadas e posições diversas.

O objetivo do presente trabalho, pois, não é menosprezar gratuitamente a noção de Estado e tributação, mas apenas dar luz a uma robusta produção intelectual que pouco se fala, mas tem muito a contribuir para o estudo do direito, economia e filosofia. Ademais, quando o assunto é tributação e redistribuição de renda, parece haver poucos pontos negativos, o que torna o debate frequentemente limitado. Porém, Hans Hoppe quebra essa hegemonia com a sua intransigente defesa intelectual do direito natural de propriedade privada e da economia de livre mercado.

Portanto, a conclusão a que se chega é clara: a tributação, sob uma perspectiva hoppeana, é eticamente indefensável e economicamente destrutiva.

\section{REFERÊNCIAS}

ATALIBA, Geraldo. Hipótese de Incidência Tributária. 6a Ed. São Paulo: Malheiros, 2014. 209 p. BASTIAT, Frédéric. A Lei. 3a Ed. São Paulo: Instituto Ludwing von Mises Brasil, 2010. 62p.

DALLARI, Dalmo de Abreu. Teoria Geral do Estado. 32a Ed. São Paulo: Saraiva, 2013. 306 p.

DEFOE, Daniel. Robinson Crusoé. Disponível em: <https://www.virtualbooks.com.br/v2/ebooks/pdf/00855.pdf>. Acesso em 30 de março de 2020 às 09:46 horas. 
GIANTURCO, Adriano. A Ciência Política: Uma Introdução. $2^{a}$ Ed. Rio de Janeiro: Forense, 2018.

HOPPE, Hans-Hermann. A Ciência Econômica e o Método Austríaco. $1^{\text {a }}$ Ed. São Paulo: Instituto Ludwing von Mises Brasil, 2010. 74p.

A Ética e a Economia da Propriedade Privada. Disponível em:

<https://www.mises.org.br/Article.aspx?id=200>. Acesso em 22 de janeiro de 2019 às 20:53 horas.

A Fraude Chamada "Estado". Disponível em:

<https://www.mises.org.br/Article.aspx?id=151>. Acesso em 16 de janeiro de 2020 às 09:35 horas.

Cultura e Liberdade - Uma Entrevista com Hans-Hermann Hoppe. Disponível em: <https://www.mises.org.br/article/1646/cultura-e-liberdade--uma-entrevista-com-hanshermann-hoppe>. Acesso em 14 de fevereiro de 2020 às 17:07 horas.

Democracia, o Deus que Falhou: A Economia e a Política da Monarquia, da Democracia e da Ordem Natural. $1^{\text {a }}$ Ed. São Paulo: Instituto Ludwing von Mises Brasil, 2014. 372p.

Entendendo o Libertarianismo de Forma Correta. Disponível em:

<https://rothbardbrasil.com/entendendo-o-libertarianismo-de-forma-correta/>. Acesso em 02 de fevereiro de 2020 às 16:55 horas.

. Ética Argumentativa: Quatro Objeções Respondidas. Disponível em:

<https://rothbardbrasil.com/etica-argumentativa-quatro-objecoes-respondidas/>. Acesso em 01 de fevereiro de 2020 às 15:33 horas.

. Imposto, Moralidade e Ética. Disponível em:

<https://www.mises.org.br/Article.aspx?id=926>. Acesso em 14 de janeiro de 2020 às 23:03 horas.

In Defense Of Extreme Rationalism: Thoughts on Donald McCloskey's The Rhetoric of Economics. The Review of Austrian Economics. Volume 3.

O Fundamento Lógico para a Privatização Total. Disponível em:

<https://www.mises.org.br/Article.aspx?id=973>. Acesso em 21 de janeiro de 2020 às 00:32 horas.

O que Deve Ser Feito. $1^{a}$ Ed. São Paulo: Instituto Ludwing von Mises Brasil, 2013, 50p.

The Economics and Ethics of Private Property: Studies in Political Economy and Philosophy. 2nd Edition. Auburn, Alabama: 1993.

. Uma Breve História do Homem: Progresso e Declínio. $1^{a}$ Ed. São Paulo: LVM Editora, 2018, 153p.

Uma Teoria do Socialismo e do Capitalismo. 2a Ed. São Paulo: Instituto Ludwing von Mises Brasil, 2013. 224p. 
IORIO, Ubiratan Jorge. Cantillon, os Ciclos Econômicos e a Não-Neutralidade da Moeda. Disponível em: < https://www.mises.org.br/Article.aspx?id=1819>. Acesso em 11 de maio de 2020 às 15:27 horas.

JOUVENEL, Bertrand de. A Ética da Redistribuição. $2^{a}$ Ed. São Paulo: Instituto Ludwing von Mises Brasil, 2012, 92p.

KARSTEN, Frank; BECKMAN, Karel. Além da Democracia. $1^{a}$ Ed. São Paulo: Instituto Ludwing von Mises Brasil, 2013, 102p.

MISES, Ludwing von. Ação Humana: Um Tratado de Economia. 3.1 ${ }^{a}$ Ed. São Paulo: Instituto Ludwing von Mises Brasil, 2010. 1019 p.

As Seis Lições. 7a Ed. São Paulo: Instituto Ludwing von Mises Brasil, 2009, p. 106.

Mises Brasil, 2012, 56p.

O Cálculo Econômico Sob o Socialismo. $1^{\text {a }}$ Ed. São Paulo: Instituto Ludwing von

RALLO, Juan Ramón. O Direito vem Antes do Estado; e a Propriedade privada Originou o Direito. Disponível em: <https://www.mises.org.br/Article.aspx?id=2670>. Acesso em 17 de fevereiro de 2020 às $14: 17$ horas.

ROCKWELL, Lew. 0 que é a Economia Austríaca?. Disponível em:

<https://www.mises.org.br/Article.aspx?id=35>. Acesso em 01 de maio de 2020 às 14:31 horas.

ROTHBARD, Murray Newton. A Anatomia do Estado. 1a Ed. São Paulo: Instituto Ludwing von Mises Brasil, 2012, 50p.

354p.

. A Ética da Liberdade. 2a Ed. São Paulo: Instituto Ludwing von Mises Brasil, 2010.

Ludwing von Mises Brasil, 2013, 106p.

ROUSSEAU, Jean-Jacques. O Contrato Social: Princípios do Direito Político. $1^{a}$ Ed. São Paulo: EDIPRO, 2011. 141p.

TOMÁS DE AQUINO, Santo. Suma Teológica. I-II, q. 92, 95 e 96. Disponível em: < http://santamariadasvitorias.org/suma-teologica/>. Acesso em 19 de abril de 2020, às 17:18 horas.

Submissão: 08/08/2021

Aceito: 18/08/2021 